\title{
Etiologia e Manejo das Doenças da Pupunheira no Brasil
}

\author{
Rudimar Mafacioli( ${ }^{(1)}$, Álvaro Figueredo dos Santos( ${ }^{(2)}$, Dauri José Tessmann ${ }^{(3)}$, João Batista Vida(3) \\ (1) Syngenta, Avenida Dr. Jaime Ribeiro da Luz, 971, loja 56, Santa Mônica, CEP 38408-188, Uberlândia-MG; (2) Embrapa Florestas, Estrada da \\ Ribeira, Km 111, CEP 83411-000, Colombo-PR, E-mail: alvaro@cnpf.embrapa.br; ${ }^{(3)}$ Universidade Estadual de Maringá - UEM, Departamento \\ de Agronomia, CEP 87020-900, Maringá-PR, E-mail: djtessmann@uem.br; jbvida@uem.br
}

\begin{abstract}
Resumo - A maioria dos problemas fitossanitários em pupunheira (Bactris gasipaes. var. gasipaes) é de ocorrência restrita a alguns plantios. Porém, com a expansão das áreas plantadas, a pressão das doenças aumenta, tanto nos viveiros de produção de mudas quanto em áreas de plantio comercial, potencializando o nível de danos causados pelas doenças. A antracnose (Colletotrichum gloeosporioides) é a enfermidade mais importante das pupunheiras no território brasileiro, mas outros patógenos como Phytophthora palmivora e Fusarium spp. vêm também ocorrendo em viveiros e em plantios. Outro problema que deve ser motivo de preocupação é a baixa qualidade sanitária das sementes utilizadas. Nesta revisão, são relatados os mais importantes resultados obtidos nas pesquisas fitopatológicas sobre a cultura, assim como os aspectos culturais mais relevantes. Discute-se a etiologia e as perspectivas para o manejo das principais doenças da pupunheira, com base em dados obtidos no Brasil e nos demais países onde a espécie é plantada.
\end{abstract}

Termos para indexação: Pupunha, doenças, pragas, manejo integrado, Bactris gasipaes.

\section{Etiology and Management of the Diseases of Peach Palm in Brazil}

\begin{abstract}
The majority of phytosanitary problems in peach palm (Bactris gasipaes var. gasipaes) are still restricted to some plantations. However, with the expansion of planted areas, the damages caused by diseases has increased in nurseries as well as in plantations. The anthracnosis (Colletotrichum gloeosporiodes) is the most important disease of peach palm in Brazil, but other pathogens (Phytophthora palmivora, Fusarium spp.) also occur in nurseries and peach palm plantations. Other phytosanitary problem is the low quality of the seeds of peach palm. Results from phytopathological studies on this plant are reported in this review including some management aspects. The etiology and management of the major diseases are discussed based on data obtained from Brazil and other countries where this forest species is planted.
\end{abstract}

Index terms: Peach palm, diseases, pests, integrated management, Bactris gasipaes.

\section{Introdução}

O palmito, ou "heart of palm", como é conhecido internacionalmente, é um produto de alto valor nos mercados interno e externo, movimentando aproximadamente 350 milhões de dólares por ano, com geração de 8 mil empregos diretos e cerca de 25 mil indiretos (BOVI, 2000). Com raras exceções, sua obtenção exemplifica o imediatismo econômico e traz como consequência a depredação de nossos recursos naturais. A quase extinção do palmiteiro (Euterpe edulis Mart.), em meados do século XX, foi devida à destruição acelerada da Mata Atlântica, que foi acompanhada pela dizimação das populações do palmiteiro e a eliminação de condições para sua regeneração, sendo que nessa época cerca de $99 \%$ do palmito comercial brasileiro procede do extrativismo, principalmente do açaí, na região do estuário do Rio Amazonas, e da juçara, na
Mata Atlântica das regiões Sul e Sudeste (BOVI, 1998; BOVI, 2000). O aumento das restrições legais, naturais e econômicas ao extrativismo cria um cenário favorável à expansão do mercado de palmito cultivado. Por isso, palmeiras mais precoces e que produzam palmito de boa qualidade têm sido pesquisadas, e dentre elas tem merecido destaque a pupunheira (Bactris gasipaes Kunth. var. gasipaes Henderson; sinonímia: Guilielma gasipaes (Kunth) Bailey; Guilielma utilis Orested) (BOVI, 1998, BOVI, 2000). A pupunheira se destaca em relação às outras espécies exploradas para a produção de palmito, por sua precocidade do primeiro corte (em torno de 18 meses), e a possibilidade de cortes anuais sucessivos, conferindo-lhe a característica de cultura perene. A espécie também tem apresentado ampla adaptação geográfica, alto perfilhamento, além de não sofrer escurecimento (oxidação) após o corte (TONET et al., 1999). 
A pupunheira pertence à Família Arecaceae, a qual agrega 205 gêneros e aproximadamente 2.500 espécies (MORA-URPI et al., 1997). Os frutos são tipo drupa, de coloração vermelha, alaranjado e amarelo. A pupunheira geralmente inicia o seu florescimento em 3 a 5 anos (MORA-URPI et al., 1997; KULCHETSCKI; GARDINGO, 2001). A planta floresce quase o ano inteiro, porém com maior intensidade durante os meses de agosto a dezembro. No litoral do Paraná, a floração inicia-se em novembro-dezembro, durando cerca de três meses. Os frutos amadurecem quatro meses depois, observando-se maior produção no período de julho a setembro (KULCHETSCHI; GARDINGO, 2001).

A pupunheira é uma planta nativa da região tropical das Américas. No território brasileiro, é nativa em toda a bacia Amazônica, compreendendo os estados do Acre, Amazonas, Pará, Maranhão, Amapá, Roraima, Rondônia e norte do Mato Grosso (BOVI, 1998; KULCHETSCHI; GARDINGO, 2001).

Acredita-se que o fruto da pupunheira foi o principal alimento de muitas comunidades de ameríndios précolombianos nas planícies tropicais úmidas, os quais domesticaram a pupunheira e a introduziram em diversas regiões da bacia Amazônica e na região noroeste da porção andina, estendendo-se até porções da América Central. Nesse processo, produziu-se uma abundante variação genética na planta (MORA-URPI et al., 1997). O processo de domesticação de $B$. gasipaes var. gasipaes baseou-se na condição de alimentação básica para os ameríndios. A sua posterior distribuição geográfica, feita igualmente pelos indígenas, como também a aplicação de diferentes critérios de seleção, promovida pela civilização pré-colombiana, ocasionaram o aparecimento de populações com algumas características diversificadas. Análises genéticas evidenciam a existência de duas raças na espécie $B$. gasipaes var. gasipaes no Brasil: Putumayo, que é a mais cultivada para a extração de palmito, e Pará (SOUZA et al., 2001). A pupunheira apresenta grande potencial comercial para a alimentação humana na forma de frutos, suprindo nutrientes como a vitamina $\mathrm{A}$, consumidos cozidos ou na forma de farinha, óleo, ração animal e também na forma de palmito (MORA-URPI et al., 1997).

A exploração de pupunha para produção de palmito é uma atividade relativamente recente e as pesquisas nesta área iniciaram no ano de 1965, no Centro Agronômico Tropical de Pesquisa e Ensino (CATIE), em Turrialba, Costa Rica (YUYAMA; MESQUITA, 2000). Segundo Mora-Urpi et al. (1997), a primeira plantação, na Costa Rica, foi feita em 1974. No Brasil, os primeiros resultados de pesquisa de produção de palmito começaram a ser divulgados a partir de 1978 (BOVI, 1998). Estima-se que foram plantados até 2000 cerca de 13 mil ha, principalmente nos estados do Acre, Espírito Santo, Bahia, São Paulo e Pará (BOVI, 1998; BOVI, 2000; SANTOS, et al., 2008)

Tendo em vista a crescente importância da pupunheira no Brasil, este trabalho objetiva contribuir para a discussão das doenças associadas a essa cultura com relação à sintomatologia, etiologia, epidemiologia e estratégias de controle.

\section{Doenças da Parte Aérea}

\section{Antracnose}

Das manchas foliares que ocorrem na cultura da pupunheira, a mais impoertante é a antracnose, causada pelo fungo Colletotrichum gloeosporioides (Penzig) Saccardo. Esse é um fungo mitospórico, ordem Melanconiales, Classe Coelomycetes; na sua fase teleomórfica, está associado com estirpes homotálicas ou heterotálicas de Glomerella cingulata (filo Ascomycota, ordem Phyllachorales) (SUTTON, 1992; ALEXOPOULOS et al., 1996; KENDRICK, 2001). A antracnose é a principal doença que vem causando danos principalmente em mudas na fase de viveiro e em plantios adultos (ALVES; BATISTA, 1981; SANTOS et al., 2000; SANTOS et al., 2001a; MAFACIOLI et al., 2003; MAFACIOLI et al., 2006). A enfermidade tem sido diagnosticada tanto nas regiões onde a planta é nativa como naquelas em que foi introduzida (SANTOS et al., 2001).

O primeiro relato de manchas foliares na pupunheira associadas com Colletotrichum spp. foi feito por Vargas e Vilaplana (1979). Esses autores relataram a ocorrência de "manchas negras" causando destruição do tecido foliar em mudas de pupunheira na Costa Rica. Da mesma forma, MoraUrpi et al. (1997) citam a ocorrência de manchas foliares escuras "black spots" associadas com Colletotrichum sp. No Brasil, Alves e Batista (1981) relataram pela primeira vez a ocorrência de antracnose em folhas de mudas de pupunheira na Amazônia, causada por Colletotrichum sp. Posteriormente, esses autores identificaram a espécie C. gloeosporioides como agente causal da doença (ALVES; BATISTA, 1983). Mota et al. (1993a; 1993b) também relataram a ocorrência de C. gloeosporioides associada com podridões em frutos da pupunheira. 
Em publicações subsequentes sobre doenças da pupunheira no Brasil, C. gloeosporioides tem sido descrito como agente causal da doença (PIZZINATTO 1996; TRINDADE et al., 1997; VÉRAS et al., 1997; POLTRONIERI et al., 1999; SANTOS et al., 2000; SANTOS et al., 2001a; SANTOS et al., 2001b). Mais recentemente, a etiologia dessa doença foi analisada com maior profundidade, verificando-se que C. gloeosporioedes é o agente causal da doença no país (MAFACIOLI et al., 2006), inclusive da existência de variabilidade patogênica desse fungo em relação à pupunheira (MAFACIOLI et al., 2008). No Paraná, esta tem sido a principal doença da cultura, causando danos principalmente em mudas e em plantios jovens com até 6 a 8 meses de idade (SANTOS et al., 2001a; SANTOS et al., 2001b) e também em frutos (VIDA et al., 2006).

A enfermidade é detectada em folhas de plantas submetidas a fatores predisponentes à doença, como mudas e plantas em substratos inadequados, estressadas, falta d'água e fertilização inadequada. Afeta as folhas jovens, caracterizando-se por manchas arredondadas e deprimidas, de coloração marrom, com anéis concêntricos de cor escura onde aparecem as estruturas do fungo. Quando mais velhas, estas lesões podem apresentar o centro claro e, devido à necrose total do tecido, pode ocorrer perfuração. Estas manchas podem ocorrer em todo o limbo foliar, levando ao secamento da folha. As lesões da antracnose servem como porta de entrada para patógenos secundários, que agravam o quadro sintomatológico da doença (SANTOS et al., 2001a; MAFACIOLI et al., 2006). Nos frutos, as manchas inicialmente são pequenas, deprimidas, cobertas com massa de esporos de aspecto rósea-clara. Quando mais velhas, as lesões aumentam em tamanho e profundidade, coalescem resultando em podridão generalizada. Em estágio mais avançado de colonização, as manchas tornam-se enegrecidas, com coloração negra intensa, devido ao desenvolvimento de outros fungos saprófitas (VIDA et al., 2006). Todos os sintomas foram observados em plantas naturalmente infectadas, em plantas nativas e diferentes campos de produção dos estados do Amazonas (ALVES; BATISTA, 1981; 1983; MOTA et al., 1993), São Paulo (PIZZINATTO et al., 1996), Pará (POLTRONIERI et al., 1999), Paraná (SANTOS et al., 2000; 2001) e Minas Gerais (VIDA et al., 2003).
A maior fonte de inóculo para disparar a doença sazonal é a permanência de folhas, brotações, inflorescências ou frutos mortos na copa de árvores. A presença do patógeno como um componente da microflora do filoplano ou em infecções latentes de tecido aparentemente saudável também representa fonte de inóculo (MASABA; WALLER, 1992). Primeiramente, esporulação, liberação e dispersão dos esporos são influenciadas pela quantidade de água livre no ambiente. Pelo menos 1-4 horas de alta umidade em temperaturas ótimas $\left(20^{\circ} \mathrm{C}\right.$ a $\left.30^{\circ} \mathrm{C}\right)$ são requeridas para a germinação de esporos e invasão dos tecidos (LOPEZ, 2001).

\section{Outras manchas foliares}

As manchas foliares causadas pelo gênero Curvularia (C. senegalensis e C. eragrostides) apresentam sintomas iniciais sob a forma de lesões circulares de coloração amarelada, translúcidas, visíveis em ambas as faces do limbo foliar, com $7 \mathrm{~mm}$ a $8 \mathrm{~mm}$ de comprimento, de forma elíptica, tornando-se gradualmente de coloração marrom-brilhante para marrom-escura. No centro da lesão aparece um halo amarelado. Quando a infecção é severa, as lesões coalescem, provocando o secamento das extremidades das folhas (BENCHIMOL; ALBUQUERQUE, 1998; SANTOS et al., 2003a; SANTOS et al., 2005).

Já a presença do fungo Bipolaris bicolor (MOREJÓN et al., 1998) em folhas de pupunheira causa manchas circulares de coloração café-escuro, com o centro mais claro e com halo clorótico. Entretanto, a patogenicidade desta espécie ainda não foi devidamente comprovada (SANTOS et al., 2005). Esses patógenos não formam estruturas de resistência, porém sobrevivem no próprio hospedeiro ou em espécies hospedeiras alternativas e restos culturais (BEDENDO, 1995; TRINDADE et al., 1997). Outra forma muito importante de sobrevivência é por meio de sementes. A grande vantagem dessa forma de sobrevivência é que o patógeno já está em contato com o hospedeiro, não estando exposto a competidores e podendo, facilmente, ser transportado a grandes distâncias (VIDA et al., 2004).

Manchas de Cladosporium sp. e Fusarium sp. têm sido também detectadas em plantios brasileiros, porém sem importância econômica (SANTOS et al., 2000).

Outras manchas foliares (Dreschlera setariae e Lasiodiplodia theobromae) de ocorrência nos plantios da Costa Rica causam manchas foliares e afetam os folíolos da pupunheira sem, contudo, provocar danos 
consideráveis na cultura (ARROYO et al., 2004) (Tabela 1). Manchas foliares provocadas por Erwinia stewarti são encontradas em plantios na Costa Rica, Panamá, Equador e Bolívia (Tabela 1), e podem estar associadas

Tabela 1. Lista de enfermidades não relatadas no Brasil. a pragas da pupunha, responsáveis pela transmissão do patógeno. Essas pragas seriam os coleópteros Rynchophorus palmarum e Metamasius hemipterus (SANCHEZ et al., 2004).

Não Relatados no Brasil

\begin{tabular}{lll}
\hline & & Vargas (1992) \\
Podridão dos frutos & Mora-Úrpi et al. (1997) \\
& Diplodia sp & Gasparotto \& Garcia (1999) \\
& Mycosphaerella sp. & \\
& Dreschlera setariae & Vargas (1992) \\
Manchas foliares & Dreschlera incurvata & Mora-Úrpi et al. (1997) \\
& Pseudomonas syringae & Arroyo et al. (2004) \\
& Erwinia stewarti & \\
\hline \multirow{2}{*}{ Sementes } & Schyzophyllum commune & Vargas (1992) \\
& Xylaria sp. & Mora-Úrpi et al. (1997) \\
\hline
\end{tabular}

\section{Síndrome da Queda dos Frutos}

Outra doença que ocorre na pupunheira é a síndrome da queda dos frutos. De etiologia ainda desconhecida, é um dos problemas mais preocupantes dos produtores de Manaus, Estado do Amazonas (MOTA; GASPAROTTO, 1995). Inicialmente, ocorre a queda dos frutos imaturos, até 20 dias após a abertura da inflorescência, onde até $50 \%$ dos frutos podem ser afetados; durante o segundo mês de desenvolvimento do fruto, pode ocorrer uma pequena queda; e nas últimas semanas antes da maturação completa geralmente ocorre mais uma queda, com menor intensidade (SANTOS et al., 2005).

\section{Podridão Negra dos Frutos}

A podridão negra é outra doença que ataca os frutos da pupunheira, doença esta que tem sido constatada na Costa Rica e no norte do Brasil, sendo causada por Ceratocystis paradoxa, normalmente encontrado na forma imperfeita (Thielaviopsis paradoxa). Ferimentos nos frutos provocados por pássaros e insetos facilitam a infecção do patógeno, com perdas de até $5 \%$ da produção (VÉRAS et al., 1997).

\section{Patógenos Radiculares}

Quanto aos patógenos radiculares, dois gêneros são importantes: Fusarium e Phytophthora. São responsáveis pela podridão da medula ou da base do estipe, ocorrendo em plantas de pupunheira com diferentes idades, desde viveiro, sendo mais frequente em plantios com idade entre seis a doze meses (SANTOS et al., 2001a). Nos plantios do Estado de São Paulo, já foram encontradas as espécies F. subglutinas, F. moniliforme, F. solani, F. anthophilum e F. oxysporum (PIZZINATTO et al., 2001), produzindo clamidósporos como estrutura de resistência (BEDENDO, 1995). A espécie $P$. palmivora já foi relatada no Brasil, nos estados do Pará (BENCHIMOL et al., 1998), Pernambuco (TAVARES et al., 1998), São Paulo (PIZZINATTO et al., 2002), Tocantins (UESUGI et al., 2003), Paraná (SANTOS et al., 2003b; SANTOS et al., 2004) e Costa Rica (ARROYO et al., 2004). A podridão da estipe da pupunheira provocada por Phytophthora palmivora (Butler) Butler ainda não constitui um problema limitante para o cultivo da pupunheira na Região Amazônica. No entanto, perdas de $30 \%$ em mudas enviveiradas e $10 \%$ em plantas 
adultas de pupunheira do tipo sem espinho, no campo, foram detectadas no Estado do Pará (BENCHIMOL et al., 2001).

Pupunheiras com sintomas de podridão da base do estipe apresentam clorose e secamento das folhas, resultante do apodrecimento dos tecidos internos da base do estipe, os quais adquirem coloração pardo-escura, levando à morte da planta (BENCHIMOL et al., 1998). As podridões provocadas por Phytophthora nas raízes e no caule ocorrem na maioria dos locais onde o solo se torna muito úmido para o crescimento normal de seus hospedeiros, e a temperatura fica ligeiramente baixa, entre $15^{\circ} \mathrm{C}$ e $23^{\circ} \mathrm{C}$ (AGRIOS, 2005). Provavelmente, a chuva e o vento são os principais fatores na epidemiologia da podridão da base do estipe da pupunheira. Os respingos provocados pela água da chuva são necessários para a liberação dos esporângios de P. palmivora da superfície dos tecidos infectados e do solo para a atmosfera, onde são dispersos pelo vento. Períodos de 24 horas ou mais de saturação do solo favorecem infecções por Phytophthora. Os esporângios e zoósporos sobrevivem no solo por curto período de tempo. Os oósporos parecem não apresentar papel importante no ciclo da podridãodo-estipe da pupunheira, embora possuam capacidade de sobrevivência longa no solo. Não há relatos sobre o ciclo de P. palmivora em B. gasipaes. Sabe-se, porém, de estudos realizados em outras culturas, que mediante condições ambientais favoráveis, como baixa drenagem e baixa fertilidade do solo, as estruturas resistentes do patógeno que sobrevivem no solo ou em restos de material vegetal entram em contato com a superfície dos tecidos basais da planta através de respingos provocados pela água da chuva, onde germinam e dão origem aos zoósporos (BENCHIMOL et al., 2001).

\section{Doenças não Relatadas no Brasil}

Na Tabela 1 é apresentada uma relação de enfermidades da pupunheira ainda não relatadas no Brasil.

\section{Estratégias de Manejo}

Para as doenças da pupunheira, deve-se ter em mente que as medidas de controle podem ser agrupadas em duas categorias: medidas culturais, que visam à manipulação dos fatores ambientais que influenciam a doença, e o controle químico, já que não se dispõe de variedades resistentes, imunes ou tolerantes.
As condições favoráveis para uma doença podem não ser as mesmas para outra, como ocorre com os fatores temperatura e umidade, mesmo assim, algumas medidas podem ser generalizadas, para a situação de viveiro:

Medidas culturais: a) como medidas profiláticas, são recomendadas: a.1) evitar a instalação de viveiros em locais que proporcionem alta umidade do solo; a.2) evitar altas densidades de mudas, que podem auxiliar no ressecamento mais rápido da folhagem, permitindo também aumentar a absorção de fungicidas pulverizados; a.3) utilizar substrato adequado: de acordo com Vida et al., (2006), dos 13 substratos testados em mudas de pupunha, a menor severidade de antracnose ocorreu para os substratos compostos de torta de filtro, solo do local, solo + composto de esterco bovino, solo + areia + composto de pó-de-serra, solo + composto 1 (folhas de grama mato-grosso e de folhas de árvores + esterco ovino), com a severidade variando de (1,4 a 4,4\%); a.4) fornecer proteção contra ventos fortes, evitando o ferimento das folhas, que favorecem a entrada do patógeno, principalmente em se tratando da antracnose (C. gloeosporioides); porém deve ocorrer boa ventilação para evitar o excesso de umidade no solo e nas plantas; a.5) quando se utilizar canteiros de semeadura para posterior repicagem, tomar o máximo de cuidado para que as raízes não fiquem expostas, evitando assim o tombamento das mudas; pode-se dar preferência para a semeadura direta, onde o substrato do recipiente é utilizado uma única vez, diminuindo a pressão de seleção na microflora do solo e o menor manejo das mudas, amenizando assim o fator de estresse das mudas; a.6) quanto ao manejo da água de irrigação, deve-se seguir a condição de não favorecer um excesso de umidade sobre as mudas e no local onde estão acondicionadas as embalagens; a.7) proporcionar adubação adequada, evitando altos teores de nitrogênio, que deixam os tecidos das plantas mais tenros e suculentos, tornando-os mais susceptíveis à invasão do patógeno. Como sugestão para adubação em viveiro, utilizar $80 \mathrm{~g}$ de uréia $+120 \mathrm{~g}$ de superfosfato simples $+20 \mathrm{~g}$ de cloreto de potássio em 20 litros de água para 200 mudas (DURIGAN; TREITNY, 2004); a.8) remover e queimar plantas e folhas doentes, evitando a dispersão de patógenos (C. gloeosporioides) (SANTOS et al., 2008).

Medidas químicas: a) tratamento químico da semente. De acordo com Pizzinatto et al., (2000), dentre todos os produtos testados para o tratamento químico das sementes 
de pupunheira, ressaltou-se o efeito do fungicida Thiran sobre a sanidade das mesmas, erradicando praticamente todos os fungos detectados nas sementes, especialmente para o Fusarium, considerado um dos principais problemas na formação de mudas e cultivo da pupunheira; b) aplicação de fungicidas no solo, antes ou após a semeadura; c) desinfestação do solo; d) para o controle de manchas foliares (antracnose): pulverizações com tiofanato metílico, seguido de tiofanato metílico + chlorothalonil (SANTOS et al., 2005), com duas a três aplicações semanais (SANTOS et al., 2001) e piraclostrobina + epoxicanazole, tetraconazole, tebuconazole, chlorotalonil, chlorotalonil + tiofanato metílico, proporcionando índice de controle de $68 \%$ a $78 \%$ em pulverizações semanais (MAFACIOLI et al., 2006). Procurar alternar os grupos químicos dos fungicidas para evitar resistência por parte dos patógenos; e) para controle de Phytophthora, produtos à base de fosetil-Al (BENCHIMOL et al., 2001) e duas a três aplicações a cada 15 dias com metalaxyl + macozeb (0,5 g p.c./l) (SANTOS et al., 2001; BENCHIMOL et al., 2001).

No campo, a pupunheira: a) não tolera áreas alagadas, devendo-se dar preferência a áreas com boa drenagem, adubação equilibrada de acordo com análise do solo; b) a irrigação preferencial é por gotejamento, favorecendo o controle de água nas plantas, evitando assim o encharcamento do solo, o que poderá contribuir para o controle de patógenos de solo como Phytophthora sp., Fusarium spp. e a bactéria Erwinia chrysantemi, esta, por sua vez, ainda não relatada no Brasil; como também o controle das manchas foliares, principalmente a antracnose, em que os respingos das gotas de irrigação favorecem a disseminação do patógeno; c) deve-se ainda tomar o cuidado de não causar ferimentos quando da operação de capinas manuais e/ou mecânicas, devido ao sistema radicular da pupunha ser muito superficial e predispor a cultura a infecções com outros patógenos. No caso da antracnose, o dano mecânico ou fisiológico ao tecido sempre resulta na ativação de infecções quiescentes. Outra consequência é a associação de Colletotrichum com outros patógenos, como observado na podridão do capulho de algodão (WALLER, 1992); d) o controle químico de plantas daninhas deverá ser efetuado em função da grande exigência hídrica por parte da cultura, evitando a competição com as plantas daninhas. Com base nos resultados obtidos por Oliveira Júnior et al. (2005) o método mais promissor para o uso de herbicida na cultura da pupunha para o manejo de plantas daninhas é a aplicação dirigida às entrelinhas; dentre os herbicidas avaliados, os mais promissores foram: diurom + MSMA, diurom + paraquat, 2,4-D, glyphosate e MSMA+ oxyfluorfen; f) em áreas onde o vento e o frio são mais constantes, utilizar quebra ventos, para que não ocorram ferimentos nas folhas e as predisponham a um estresse, favorecendo o ataque de patógenos.

\section{Considerações Finais}

A maioria dos problemas fitossanitários em pupunheira é de ocorrência restrita a alguns plantios. Em plantios, casos esporádicos são estimulados por condições adversas locais, que são observadas de maneira isolada no campo, em plantas estressadas, raramente ocorrendo em toda a plantação. Alguns desses estresses são consequência de períodos secos e de baixas temperaturas que coincidem com os transplantes; drenagem deficiente dos solos; e desequilíbrio nutricional da planta. Porém, com o aumento de áreas plantadas, pode-se esperar o aumento da pressão das doenças.

Outro problema que deve ser motivo de preocupação é a baixa qualidade sanitária da semente utilizada, havendo necessidade de pesquisas para o desenvolvimento de protocolos de tratamento.

Atenção especial deve ser dada aos viveiros de produção de mudas, onde geralmente os danos das doenças, principalmente de doenças foliares, são mais severos devido à alta densidade de plantas e ao acúmulo de umidade. As doenças causam redução na quantidade e qualidade das mudas produzidas.

\section{Referências}

AGRIOS, G. N. Plant Pathology. California, USA: Academic Press, 2005. 922 p.

ALEXOPOULOS, C.J.; MIMS, C.W.; BLACKWELL, M. Introdutory Mycology. 4ed. New York, John Wiley \& Sons, 1996. 869 p.

ALVES, M. L. B.; BATISTA, M. F. Antracnose da pupunha (Bactris gasipaes H.B.K.). Fitopatologia Brasileira, Brasília, v. 6, p. $572,1981$.

ARROYO, C.; ARAUZ, L. F.; MORA, J. Incidência de enfermedades en pejibaye (Bactris gasipaes Kunth) para palmito 1. Agronomia Mesoamericana, v. 15, p. 61-68, 2004. 
BEDENDO, I. P. Manchas foliares. In: KIMATI, H.; AMORIM, L.; BERGAMIN, F. A.; REGARGO, L. E. A.; REZENDE, J. A. M. Manual de Fitopatologia - doenças das plantas cultivadas. v. 2. 3.ed. São Paulo, Editora Agronômica Ceres, 1995a. p.848-858.

BEDENDO, I. P. Doenças vasculares. In: KIMATI, H.; AMORIM, L.; BERGAMIN, F. A.; REGARGO, L. E. A.; REZENDE, J. A. M. Manual de Fitopatologia - doenças das plantas cultivadas. v. 2. 3.ed. São Paulo, Editora Agronômica Ceres, 1995b. p.838847.

BENCHIMOL, R. L.; ALBUQUERQUE, F. C. Ocorrência de Curvularia eragrostide em mudas de pupunheira no estado do Pará. Fitopatologia Brasileira, Brasília, v. 23, p. 80, 1998.

BENCHIMOL, R. L.; ALBUQUERQUE, F. C.; MULLER, C. H. Podridão da base do estipe da pupunheira causada por Phytophthora palmivora. Fitopatologia Brasileira, Brasília, v. 23, p.181, 1998.

BENCHIMOL, R. L.; ALBUQUERQUE, F. C.; POLTRONIERI, L. S.; TRINDADE, D. R.; MÜLLER, C. H. Podridão-do-estipe da pupunheira. In: LUZ, E. D. M.; SANTOS, A. F.; MATSUOKA, K.; BEZERRA, J. L. (Eds.) Doenças causadas por Phytophthora no Brasil. Campinas, Livraria e Editora Rural. 2001. P.609-628.

BOVI, M. L. A. Palmito pupunheira: informações básicas para cultivo. Campinas: Instituto Agronômico de Campinas. Boletim Técnico, 173. 1998. 50p.

BOVI, M. L. A. O Agronegócio Palmito de Pupunha. O Agronômico, Campinas, v. 52, n. 1, p. 10-12, 2000.

DURIGAN, M. E.; TREITNY, M. R. Sementes e mudas pupunha e palmeira real. In: ENCONTRO PARANAENSE SOBRE PALMITOS CULTIVADOS, 1., 2002, Pontal do Paraná. O agronegócio pupunha e palmeira real: anais. Colombo: Embrapa Florestas, 2004. (Embrapa Florestas. Documentos, 105). Editado por Alvaro Figueredo dos Santos. p. 85-90.

GARCIA, A.; SOUZA, V. F. As doenças de pupunheira (Bactris gasipaes) na Amazônia e medidas de controle. Porto Velho: EMBRAPA-CPAF, Rondônia 1998. 13p. (EMBRAPA-CPAF Rondonia. Circular Tecnica, 41).

KENDRICK, B. The Fifth Kingdom. $3^{\mathrm{a}}$. ed. Mycologue Publications, 2001. 380p.

KULCHETSCKI, L.; GARDINGO, J. R. Aspectos ecológicos, botânicos e morfológicos. In: KULCHETSCKI, L.; CAHIMSOHN, F. P.; GARDINGO, J. R. Palmito Pupunheira (Bactris gasipaes Kunth), Ponta Grossa, UEPG, p.148, 2001.

LOPEZ, A. M. Q. Taxonomia, patogênese e controle de espécies do gênero Colletotrichum. Revisão Anual de Patologia de Plantas, v. 9, p.291-338, 2001.

MAFACIOLI, R.; SANTOS, A. F.; TESSMANN, D. J.; VIDA, J. B.; NUNES, W. M. C. Variabilidade patogênica de isolados de Colletotrichum gloeosporioides da pupunheira. Fitopatologia Brasileira, Brasília, v. 28, supl., p. 232-233, ago. 2003. Resumo apresentado no Congresso Brasileiro de Fitopatologia, 36, 2003.

MAFACIOLI, R.; TESSMANN, D. J.; SANTOS, A. F. dos; VIDA, J. B. Caracterização morfo-fisiológica e patogenicidade de Colletotrichum gloeosporioides da pupunheira. Summa Phytopathologica, v. 32, p.113-117, 2006a.
MAFACIOLI, R.; TESSMANN, D. J.; SANTOS, A. F. dos; VIDA, J. B. Controle químico da antracnose em mudas de pupunheira em viveiro. Boletim de Pesquisa Florestal, Colombo, n. 52, p. 151-156, 2006b.

MAFACIOLI, R.; TESSMANN, D. J.; SANTOS, A. F. dos ; VIDA, J. B. Variabilidade patogênica e efeito de carboidratos no crescimento micelial, esporulação e agressividade de Colletotrichum gloeosporioides da pupunheira. Summa Phytopathologica, Botucatú, v. 34, n. 1, p.18-21, 2008

MASABA, D.; WALLER, J. M. Coffe berry diseases: the current status. In: BAILEY, J. A.; JEGER, M. J. (Eds.). Colletotrichum: biology, pathology and control. England, $\mathrm{CAB}$ International Wallingford 1992, p. 237-249.

MORA-URPI, J.; WEBER, J. C.; CLEMENT, R. C. Peach palm: Bactris gasipaes Kunth. Rome: IPGR, 1997. 83 p. (Promoting the Conservation and Use of Underutilized and Neglected Crops, 20).

MOREJÓN, K. R.; KIMATI, H.; FANCELLI, I. Bipolaris bicolor (Mitra) Shoenmaker: Espécie associada a manchas foliares de la palm pupunha (Bactris gasipaes Kunth) em Brasil. Revista IberoAmericana de Micologia, v. 15, p. 55-57, 1998.

MOTA, A. M.; GASPAROTTO, L. Dinâmica da queda precoce de frutos de pupunha. Fitopatologia Brasileira, Brasília, v. 20, supl., p. $377,1995$.

OLIVEIRA JÚNIOR, R. S.; CONSTANTIN, J.; INOUE, M. H.; CARREIRA, S. A. M.; DVORANEN, E. C.; TESSMANN, D. J. Diagnóstico e perspectivas do manejo de plantas daninhas na cultura da pupunha no Noroeste do Estado do Paraná. Acta Scientiarum Agronomia, v. 27, p. 335-341, 2005.

PIZZINATTO, M. A.; BOVI, M. L . A.; SOAVE, J.; SPIERING, S. H.; BINOTTI, C. S. Tratamento químico de sementes de pupunheira (Bactris gasipaes): efeitos na sanidade, germinação e vigor. Summa Phytopathologica, Botucatu, v. 26, p. 42-47, 2000.

PIZZINATTO, M. A.; BOVI, M. L. A.; SPIERING, S. H.; BINOTTI, C. S. Patogenicidade de cinco espécies de Fusarium a planta de pupunheira (Bactris gasipaes). Summa Phytopathologica, Botucatu, v. 27, n.263-268, 2001.

PIZZINATTO, M. A.; BOVI, M. L. A.; FEICHTENBERGER, E.; SPIERING, S .H. Ocorrência da podridão do estipe em pupunheira, causada por Phytophthora palmivora, no Estado de São Paulo. Summa Phytopathologica, Botucatu, v. 28, p. 363365, 2002.

POLTRONIERI, L. S.; GASPAROTO, L.; BENCHIMOL, R. L. Doenças da cultura da pupunheira. In: DUARTE, M. L. R. Doenças de plantas no trópico úmido Brasileiro. I, Plantas industriais, Belém: EMBRAPA, p. 209-217, 1999.

SANCHEZ, E.; WANG, A.; URIBE, L.; PIZARRO, R.; CARTAGENA, L.V.; BOGANTES, A.; MEXZON, R.; OQUENDO, C. A. Bacteriosis del Palmito. 2004. Disponível em: < http://www.pejibaye.ucr.ac.cr>. Acesso em: 19/06/2006. Verificar o caminho correto.

SANTOS, A. F.; CORRÊA, C.; NEVES, E. J. M. (Ed.) Palmeiras para produção de palmito: juçara, pupunheira e palmeira real. Colombo: Embrapa Florestas, 2008. 190 p. 
SANTOS, A. F.; TESSMANN, D. J.; VIDA, J. B.; NUNES, W. M. C. As doenças da pupunheira (Bactris gasipaes Kunth): antracnose e podridão da medula. Embrapa Florestas. 2001. 3 p. Colombo, PR. (Embrapa Florestas. Comunicado Técnico, 63).

SANTOS, A. F.; BEZERRA, J. L.; TESSMANN, D. J.; POLTRONIERI, L. S. Ocorrência de Curvularia senegalensis em Pupunheira e Palmeira Real no Brasil. Fitopatologia Brasileira, Brasília, v. 28, p. 204, 2003 a.

SANTOS, A. F.; LUZ, E. D. M. N.; FINATO, P.; TESSMANN, D. J.; VIDA, J. B. Caracterização de Phytopthora palmivora e sua patogenicidade à pupunheira no estado do Paraná. Fitopatologia Brasileira, Brasília, v. 28, p. 225, 2003 b.

SANTOS, A. F.; LUZ, E. D. M. N.; FINATO, P.; TESSMANN, D. J.; VIDA, J. B. Primeiro relato da podridão do estipe da pupunheira, causada por Phytophthora palmivora, no estado do Paraná. Fitopatologia Brasileira, Brasília, v. 29, p. 680-682, 2004.

SANTOS, A. F.; TESSMANN, D. J.; SILVA, A. J. C.; VIDA, J. B.; MAFACIOLI, R. Doenças em palmeiras para palmito. In: SEMINÁRIO DE ATUALIDADES DE PROTEÇÃO FLORESTAL, 2., 2005, Blumenau. Palestras e resumos. [Blumenau]: FURB, 2005. 1 CD-ROM. Palestra (Doenças florestais). Co-promoção: Embrapa Florestas.

SANTOS, A. F.; TESSMANN, D. J.; JACCOUD FILHO, D. S.; VIDA, J. B. Doenças da pupunheira. In: KULCHETSCHI, L.; CHANIMSOHN, F. P.; GARDInGO, J. R. Palmito Pupunha (Bactris gasipaes). Ponta Grossa, UEPG. 2001. 148 p.

SUTTON, B. C. The genus Glomerella and its anamorph. In: BAILEY, J. A.; JEGER, M. J. (Eds.). Colletotrichum: Biology, pathology and control. England, CAB Intenational Wallingford, 1992. p. 1-26.

TAVARES, S. C. C. H.; NASCIMENTO, A. R.; LIMA, J. A. S.; MENEZES, W. A.; CRUZ, S. C. Doenças da pupunha em áreas irrigadas na região do sub-médio São Francisco. Fitopatologia Brasileira, Brasília, v. 23, supl., p. 286, 1998.

TONET R. M.; FERREIRA, L. G. S.; OTOBONI, J. L. M. A. Cultura da Pupunha. Campinas: CATI, 1999. 44 p. (CATI. Boletim técnico, 237).

TRINDADE, D. R.; SILVA, H. M.; POLTRONIERI, L. S.; GASPAROTO, L. Palmáceas: Controle de doenças. In: VALE, F. X. R. do; ZAMBOLIN, L. Controle de doenças de palmas: grandes culturas. 1 ed. Viçosa: UFV, 1997, v. 2, p. 865-878.
UESUGI, C. H.; SANTOS, G. R.; CAFÉ FILHO, A. C. C. Ocorrência de Phytophthora palmivora no estado do Tocantins. Fitopatologia Brasileira, Brasília, v. 28, supl., p. 225, 2003.

VARGAS, E. La murchitez del pejibaye, una nueva enfermedad en Costa Rica. Boletín Pejibaye, Guilielma, v. 9, n. 1, p. 1-3, 1992. (Serie Técnica)

VÉRAS, S. M.; LIMA, M. I. P. M,; GASPAROTTO, L. Doenças de fruteiras da Amazônia. In: KIMATI, H.; AMORIM, L.; BERGAMIN, F. A.; REGARGO, L. E. A.; REZENDE, J. A. M. Manual de Fitopatologia: doenças das plantas cultivadas. $3^{\mathrm{a}}$. ed. São Paulo: Editora Agronômica Ceres. v. 2, 1997, p. 406-410.

VIDA, J. B.; TESSMANN, D. J.; MAFACIOLI, R.; VERZIGNASSI, J. A.; SANTOS, A. F. Colletotrichum gloeosporioides causando antracnose em frutos de pupunheira nos estados de Minas Gerais e Paraná. Summa Phytopathologica [online], v. 32, n. 4, p. 379-380, 2006. Disponível em: http://www.scielo.br/scielo.php?pid=S0100$54052006000400011 \&$ script $=$ sci_arttext\&tlng=en]. doi: 10.1590/S0100-54052006000400011.

VIDA, J. B.; ZAMBOLIN, L.; TESSMANN, D. J.; BRANDÃO FILHO, J. U. T.; VERZIGNASSI, J. R.; CAIXETA, M. Manejo de doenças de plantas em cultivo protegido. Fitopatologia Brasileira, Brasília, v. 29, p. 355-372, 2004.

VIDA, J. B.; MARTINS, S. S.; TESSMANN, D. J.; MAFACIOLI, R.; SANTOS, A. F.; BONALDO, S. M.; CAIXETA, M. P. Severidade de antracnose (Colletotrichum gloeosporioides) em mudas de pupunheira produzidas em diferentes substratos. Summa Phytopathologica, v. 32, supl., S. 46, feb. 2006. Edição dos resumos do 29o Congresso Paulista de Fitopatologia, 2006, Botucatu.

YUYAMA, K.; MESQUITA, S. M. S. Crescimento de mudas de pupunheira (Bactris gasipaes) transplantadas em diferentes estádios de plântula, substratos e volume de substrato. Acta Amazônica, Manaus, v. 30, p. 515-520, 2000.

WALLER, J. M. Colletotrichum diseases of perennial and other cash crops. In: BAILEY, J. A.; JEGER, M. J. (Eds.) Colletotrichum: biology, pathology and control. England, $\mathrm{CAB}$ International Wallingford, 1992, p. 167-185.

Recebido em 17 de novembro de 2008 e aprovado em 06 de agosto de 2009 